\title{
IMproving the imPlemEntation of cuRrent guidelines for the mAnagement of major coronary hearT disease rlsk factors by multifactorial interVEntion. The IMPERATIVE renal analysis
}

\author{
Vasilios G. Athyros ${ }^{1}$, Apostolos I. Hatzitolios², Asterios Karagiannis', Christos Savopoulos², \\ Niki Katsiki', Konstantinos Tziomalos², Aikaterini Papagianni ${ }^{3}$, Anna Kakafika ${ }^{4}$, Thomas D. Gossios ${ }^{5}$, \\ Dimitri P. Mikhailidis'; for the IMPERATIVE Collaborative Group
}

\begin{abstract}
12nd Propedeutic Department of Internal Medicine, Aristotelian University of Thessaloniki, Hippocration Hospital, Thessaloniki, Greece

$21^{\text {st }}$ Propedeutic Department of Internal Medicine, Medical School, Aristotle University of Thessaloniki, AHEPA Hospital, Thessaloniki, Greece

32Department of Nephrology, Aristotelian University of Thessaloniki, Hippocration Hospital, Thessaloniki, Greece

4Department of Internal Medicine, Euro-Clinic, Thessaloniki, Greece

5Inherited Cardiovascular Disease Unit, The Heart Hospital, London, United Kingdom ${ }^{6}$ Department of Clinical Biochemistry, Vascular Prevention Clinic, Royal Free Hospital, University College Medical School, University College London, United Kingdom
\end{abstract}

Submitted: 12 September 2011

Accepted: 20 October 2011

Arch Med Sci 2011; 7, 6: 984-992

DOI: 10.5114/AOMS.2011.26610

Copyright $\odot 2011$ Termedia \& Banach

\begin{abstract}
Introduction: The short-term effects of multifactorial intervention for cardiovascular disease (CVD) prevention on renal function and serum uric acid (SUA) levels in patients with stage 3 chronic kidney disease (CKD) and multiple CVD risk factors are unclear. The aim of the study was to prospectively assess these effects.

Material and methods: This post hoc analysis of 5 "best practice" studies involved patients with multiple CVD risk factors. Estimated glomerular filtration rate (eGFR) was assessed using the Modification of Diet in Renal Disease (MDRD) formula. Among the 4,153 patients, 1,235 (29.7\%) had stage 3 CKD (eGFR between 30 and $59 \mathrm{ml} / \mathrm{min} / 1.73 \mathrm{~m}^{2}$ ). A baseline visit was followed by a concerted effort from previously trained physicians to improve adherence to lifestyle advice and optimize drug treatment, including a statin, for all vascular risk factors. After 6 months eGFR and SUA levels were re-evaluated.

Results: The intervention improved compliance to lifestyle measures and increased the use of evidence-based medication, including a statin. There was also a $5.6 \%$ increase in eGFR $(p<0.001)$ in patients with stage 3 CKD and a $6.1 \%$ reduction in SUA levels $(p<0.001)$. Among patients with stage 3 CKD, $127(10.3 \%)$ improved to stage 2 CKD and $9(0.7 \%)$ advanced to stage 4 CKD by the end of the 6-month study period. There were no major side-effects.

Conclusions: Multitargeted intervention, including a statin, may improve renal function and reduce SUA levels within 6 months, thus offsetting 2 potential CVD risk factors in high-risk patients.
\end{abstract}

Key words: renal function, uric acid, dyslipidaemia, diabetes mellitus, hypertension, metabolic syndrome, multifactorial intervention, statin.

\author{
Corresponding author: \\ Dimitri P. Mikhailidis \\ MD, FFPM, FRCP, FRCPath \\ Department \\ of Clinical Biochemistry \\ Royal Free Hospital Campus \\ University College \\ Medical School \\ University College London \\ Pond Street, London NW3 \\ 2QG, United Kingdom \\ Phone: +44 2078302258 \\ Fax: +44 2078302235 \\ E-mail: mikhailidis@aol.com
}




\section{Introduction}

The world-wide prevalence of chronic kidney disease (CKD) is high and is increasing rapidly [1]. In 2010, 26 million American adults had CKD and millions of others are at increased risk. According to the National Kidney Foundation classification [1-5], more than 8 million had stage 3 CKD and $0.5 \%$ had stage 4 or 5 CKD [1-5].

Total mortality, cardiovascular disease (CVD) events and hospitalizations markedly increase as renal function declines [6-8]. Even moderately decreased estimated glomerular filtration rate (eGFR) and low levels of albuminuria predict CVD and all-cause mortality in the general population [9]. This has led to the suggestion to incorporate kidney function in the Framingham equation to improve CVD risk stratification [10].

There are considerable gaps in our knowledge on how to manage patients with CKD [11]. We showed that statins improve renal function [12] and reduce serum uric acid (SUA) levels [13] in patients with CVD [12] and in those with CVD and metabolic syndrome (MetS) or diabetes mellitus (DM) [14-16]. In the primary prevention setting, we recently reported that long-term (42 months) multifactorial intervention, including atorvastatin, improves renal function and reduces CVD events in patients with MetS but without CVD or DM [17]. The other relevant studies in this field are considered in the discussion section.

Dyslipidaemia may accelerate the decline of renal function, and the coexistence of MetS, DM, or hypertension is also associated with a faster rate of decline, rendering early and effective interventions of utmost importance [18]. This was also suggested by the findings of the Study of Heart and Renal Protection (SHARP), where pre-dialysis renal function could not be improved by lipid-lowering therapy [19].

The present analysis of 5 previous "best practice" studies was undertaken to investigate the early (6-month) effects of multifactorial treatment on renal function and SUA levels in high-risk patients with multiple CVD risk factors.

\section{Material and methods}

The present study is a post hoc analysis of changes in renal function in 5 independent studies carried out from 2005 to 2010 [17, 20-23]. One study [17] was performed by the Hellenic Atherosclerosis Society and the other 4 studies were performed [2023] under the auspices of the Northern Greece Bureau (Authority) of the Ministry of Health, the Hellenic Atherosclerosis Society and the Greek Society of General Practitioners. All studies received ethical approval and informed consent was obtained from all subjects before enrolment. The studies incorporated in the present analysis are:
1) Assessing The Treatment Effect in Metabolic syndrome without Perceptible diabeTes (ATTEMPT) study, which included patients with MetS but no DM or CVD [17];

2) implementation of strategy for the management of overt dyslipidemia (IMPROVE-dyslipidemia) study, which included patients with dyslipidaemia with or without DM, with or without CVD [20];

3) standardized arrangement for a guideline-driven treatment of the metabolic syndrome (SAGEMETS) study, which included patients with MetS but no CVD [21];

4) implementation of guidelines for the management of arterial hypertension (IMPULSION) study, which included patients with hypertension with or without DM but no CVD [22];

5) initiative for a new diabetes therapeutic approach in a Mediterranean country (INDEED) study, which included patients with diabetes but no CVD [23].

\section{Endpoints}

The primary endpoint of the studies was the effect of multiple interventions on estimated CVD risk. The primary endpoint of this post hoc joint analysis was to investigate the early effect of multifactorial treatment on renal function (eGFR) 6 months after intervention initiation. The secondary endpoint was the effect of this treatment on SUA levels.

\section{Definition of MetS}

This was according to the American Heart Association/National Heart, Lung, and Blood Institute criteria [24].

\section{Study design - study cohort}

All 5 studies had a similar protocol. They were designed as "best practice" prospective studies. Physicians from teaching hospitals (secondary care) or health centres (primary care) recruited consecutive consenting patients with DM, MetS, hypertension or dyslipidaemia who attended their outpatient clinics. A total of 4,153 patients were included in the present intention-to-treat analysis. The 1,123 patients who were included in the ATTEMPT study [17] were followed up for 3,5 years, whereas the patients in the other 4 studies were followed up for 6 months. However, in this post-hoc IMPERATIVE analysis, ATTEMPT patients were evaluated for the first 6 months, similarly to those of the other studies. In all studies all patients were followed monthly by their physicians for at least 6 months. Among the entire analysis population $(n=4,153) 1,235(29.7 \%)$ had stage 3 CKD according to the National Kidney Foundation definition [2], i.e. eGFR between 30 and $59 \mathrm{ml} / \mathrm{min} / 1.73 \mathrm{~m}^{2}$. The eGFR was calculated with 
the Modification of Diet in Renal Disease (MDRD) formula [25]. No patient had stage $4(15-29 \mathrm{ml} / \mathrm{min} /$ $\left.1.73 \mathrm{~m}^{2}\right)$ or $5\left(<15 \mathrm{ml} / \mathrm{min} / 1.73 \mathrm{~m}^{2}\right)$, according to the protocol of the original studies, while 1,424 patients (34\%) had stage $2\left(60-89 \mathrm{ml} / \mathrm{min} / 1.73 \mathrm{~m}^{2}\right), 912(22 \%)$ stage 1 (> $90 \mathrm{ml} / \mathrm{min} / 1.73 \mathrm{~m}^{2}+$ evidence of kidney damage) CKD [2], and 582 (14\%) had normal renal function without any evidence of kidney damage.

At the first visit, the personal and family medical history and the drug treatment were recorded on a specifically designed 1-page form. A physical examination was also carried out. Subjects were then invited to undergo laboratory tests at the hospital after a $12 \mathrm{~h}$ fast, at which time a second physical examination was performed.

\section{Intervention}

Before the study initiation and during the study, physicians attended a total of 7 educational meetings. In 4 meetings, current guidelines for the management of hypertension, dyslipidaemia, MetS, DM and obesity were presented, specific diets based on the Greek variation of the Mediterranean diet were shown and up-to-date treatment protocols were discussed. The other 3 meetings were for the solving of technical problems during the study.

During the 6-month follow-up, an intensification of treatment in terms of lifestyle advice, administration of new drugs or titration of already prescribed drugs was implemented, aiming to reach multiple treatment targets. The physician advised each patient to follow a healthier lifestyle and to adhere to drug treatment. Patients were encouraged to follow a modified Mediterranean diet as described in a brochure. Adherence to this diet was assessed using a 10-unit scale. The study protocol advised the use of orlistat in obese patients (body mass index $(\mathrm{BMI})>30 \mathrm{~kg} / \mathrm{m}^{2}$ ) and in overweight patients who did not lose at least $4 \mathrm{~kg}$ during the first 3 months. Apart from the brochure including advice on how to achieve these goals, patients also received education from dieticians (mainly in hospitals) or from physicians (mainly in health centres) who were also educated in providing nutritional advice. Furthermore, special attention was drawn to quitting smoking using certain appropriate methods (i.e. counselling, psychological support and nicotine replacement treatments).

\section{Follow-up}

In Greece, prescriptions have to be "refilled" monthly, and most of the drugs used have 90\% reimbursement. Consequently, patients had to visit their physician every month. During these 6 visits (after the start of the study), the physician tried to improve the control of CVD risk factors (e.g. by lifestyle advice, administration of new drugs, dose titration or change of prescribed drugs). There was a lifestyle evaluation and dose titration visit at the $6^{\text {th }}$ treatment week and patients were then followed at monthly intervals. At the $6^{\text {th }}$ treatment month (the final visit), the physician completed a 1-page form for each patient that included 2 questions. Does the patient still have CVD risk factors? And if yes, what did the physician do about it? The physician was aware of this question from visit 1 and we believe that this was a motivating factor.

There was no "control" group because all patients were at high CVD risk. It was therefore deemed unethical to deprive them of appropriate treatment. We used as control values those at baseline before the implementation of the multifactorial intervention.

\section{Laboratory-based assessment}

Blood samples were collected from an antecubital vein between 8 and $10 \mathrm{am}$, in a sitting position, after a $12 \mathrm{~h}$ fast. Serum levels of total cholesterol, high density lipoprotein cholesterol (HDL-C) and triglycerides (TGs) were measured. Serum low density lipoprotein cholesterol (LDL-C) levels were calculated with the Friedewald formula (LDL-C $[\mathrm{mg} / \mathrm{dl}]=\mathrm{TC}[\mathrm{mg} / \mathrm{dl}]-(\mathrm{TG}[\mathrm{mg} / \mathrm{dl}] / 5+\mathrm{HDL}-\mathrm{C}$ $[\mathrm{mg} / \mathrm{dl}]))$. The non-HDL-C value was obtained by subtracting the HDL-C value from that of total cholesterol. Serum creatinine ( $\mathrm{SCr}$ ) was measured using the Jaffe method. The same method was used in all patients, and there were no changes in methodology during any of the interventional periods. Serum alanine aminotransferase (ALT), aspartate aminotransferase (AST), $\gamma$-glutamyl transpeptidase $(\gamma$-GT), alkaline phosphatase (AP), creatine phosphokinase (CPK) levels and SUA levels were also assessed. eGFR $\left(\mathrm{ml} / \mathrm{min} / 1.73 \mathrm{~m}^{2}\right)$ was measured using the Modification of Diet in Renal Disease equation: $\mathrm{eGFR}=175 \times(\mathrm{SCr}[\mathrm{mg} / \mathrm{dl}])^{-1.154} \times($ age [years] $)^{-0.203} \times(0.742$ if female) [http://www.nkdep. nih.gov/professionals/gfr_calculators/idms_con. htm] [25]. All laboratories that performed these tests followed the criteria of the World Health Organization Lipid Reference Laboratories and fulfilled internal and external validity control criteria. All measurements in the same centre were performed with the same methods in the same laboratory, so that results would be comparable.

\section{Statistical analysis}

The analysis was carried out with the SPSS 19.00 software package (SPSS Inc., Chicago, IL). Variables both at baseline and 6 months later were normally distributed, as evaluated with the KolmogorovSmirnov test, so the results are presented as mean \pm SD. The paired Student $t$-test and the $\chi^{2}$ test were used to compare continuous and categorical vari- 
ables, respectively. A two-tailed $p<0.05$ was considered significant.

\section{Results}

Among the 4,153 patients, 1,524 had CVD or DM or both (secondary prevention or equivalent) and 2,629 were free of both CVD and DM (primary prevention). Among the 4,153 patients, 29.7\% $(n=1,235)$ had stage 3 CKD. Among those, 23.1\% $(n=285)$ had DM and $15.3 \%(n=189)$ had overt CVD. Among stage 3 CKD patients, the following drugs were used: all patients $(n=1,235)$ were on statins. Hypertension was primarily managed with angiotensinconverting enzyme inhibitors (ACE-I) or angiotensin receptor blockers (ARBs; $45 \%$ and 31\%, respectively), and if needed with calcium channel blockers (CCB, 30\%) or low-dose hydrochlorothiazide (12.5 $\mathrm{mg} /$ day, $25 \%)$. If hypertension was not controlled, selective $\beta$-blockers (28\%), centrally acting (14\%) or any other antihypertensives (9\%) were used. Orlistat was used in 512 patients with a $\mathrm{BMI}>30$ $\mathrm{kg} / \mathrm{m}^{2}$. Metformin, sulfonylureas and insulin were used in patients with impaired fasting glucose or DM. Metformin was also used in obese patients

Table I. Change in measured parameters in patients $(n=1,235)$ with stage 3 chronic kidney disease (CKD, estimated glomerular filtration rate $30-59 \mathrm{ml} / \mathrm{min} /$ $1.73 \mathrm{~m}^{2}$ ) among the 4,153 patients included in the 5 studies

\begin{tabular}{|c|c|c|c|}
\hline Parameter & Baseline & 6 months & Value of $p$ \\
\hline Age [years] & $57 \pm 6$ & - & - \\
\hline Male gender [\%] & 47 & - & - \\
\hline Family history of CVD [\%] & 26 & - & - \\
\hline Smoking [\%] & 29 & 23 & $<0.001$ \\
\hline Body mass index $\left[\mathrm{kg} / \mathrm{m}^{2}\right]$ & $30 \pm 5$ & $27 \pm 4$ & $<0.001$ \\
\hline Body weight [kg] & $81 \pm 7$ & $76 \pm 5$ & $<0.001$ \\
\hline Waist circumference $[\mathrm{cm}]$ & $99 \pm 7$ & $95 \pm 6$ & $<0.001$ \\
\hline $\begin{array}{l}\text { Systolic blood pressure } \\
{[\mathrm{mmHg}]}\end{array}$ & $145 \pm 11$ & $132 \pm 9$ & $<0.001$ \\
\hline $\begin{array}{l}\text { Diastolic blood pressure } \\
{[\mathrm{mmHg}]}\end{array}$ & $91 \pm 10$ & $82 \pm 6$ & $<0.001$ \\
\hline Blood glucose $[\mathrm{mg} / \mathrm{dl}]$ & $110 \pm 16$ & $97 \pm 12$ & $<0.001$ \\
\hline Total cholesterol [mg/dl] & $232 \pm 36$ & $175 \pm 21$ & $<0.001$ \\
\hline Triglycerides [mg/dl] & $186 \pm 37$ & $124 \pm 29$ & $<0.001$ \\
\hline $\mathrm{HDL}-\mathrm{C}[\mathrm{mg} / \mathrm{dl}]$ & $45 \pm 14$ & $48 \pm 7$ & $<0.001$ \\
\hline $\mathrm{LDL}-\mathrm{C}[\mathrm{mg} / \mathrm{dl}]$ & $150 \pm 28$ & $103 \pm 19$ & $<0.001$ \\
\hline $\begin{array}{l}\text { Estimated glomerular } \\
\text { filtration rate } \\
{\left[\mathrm{ml} / \mathrm{min} / 1.73 \mathrm{~m}^{2}\right]}\end{array}$ & $50 \pm 6$ & $53 \pm 5$ & $<0.001$ \\
\hline Serum uric acid [mg/dl] & $7.1 \pm 2.3$ & $6.7 \pm 2.1$ & $<0.001$ \\
\hline
\end{tabular}

CVD - cardiovascular disease, HDL-C - high density lipoprotein cholesterol, $L D L-C-$ low density lipoprotein cholesterol $(n=452)$ with an eGFR $>45 \mathrm{ml} / \mathrm{min} / 1.73 \mathrm{~m}^{2}$. The drug treatment results refer to the $6^{\text {th }}$ week (titration visit) to the $6^{\text {th }}$ month period (end of study).

At the $6^{\text {th }}$ treatment month, there was an improvement (compared with baseline) in all CKD and CVD risk factors in stage 3 CKD patients, (body weight, fasting plasma glucose (FPG), systolic and diastolic blood pressure, and lipid values; Table I).

Those with stage 1 and 2 CKD had lower SUA levels, lower BMI, and a lower incidence of MetS, compared with stage 3 CKD patients. However, there were no differences in smoking status, gender, drug categories used, or in adherence to lifestyle advice. The dropout rate was similar at all stages of CKD and there were no clinical events in patients at any stage of CKD during the study.

In stage 3 CKD patients, multifactorial treatment resulted in a $5.6 \%$ increase in eGFR (from $50 \pm 6$ to $\left.53 \pm 5 \mathrm{ml} / \mathrm{min} / 1.73 \mathrm{~m}^{2} ; p<0.001\right)$ and in a $6.1 \%$ reduction in SUA levels (from $7.1 \pm 2.3$ to $6.7 \pm 2.1$ $\mathrm{mg} / \mathrm{dl} ; p<0.001$ ) (Table I and Figure 1). Among the stage 3 CKD patients, 127 (10\%) improved to stage 2 CKD and $9(0.7 \%)$ advanced to stage 4 CKD by the end of the 6-month study period. There were no major side-effects of drug treatment.

\section{Discussion}

The IMPERATIVE analysis included both primary and secondary prevention patients with hypertension, dyslipidaemia, MetS and DM, alone or (mainly) in combination, and showed that a multifactorial approach improves the use of evidence-based treatment. In the overall population $(n=4,153)$, multifactorial treatment was not related to a significant change in renal function. However, in patients $(n=1,235)$ with stage 3 CKD a significant $5.6 \%$ $(p<0.001)$ increase in eGFR and a $6.1 \%$ reduction $(p<0.001)$ in SUA levels were recorded, thus offsetting 2 predictors of CVD within 6 months.

Glomerular filtration rate is expected to decrease with time [26] and this process is influenced by

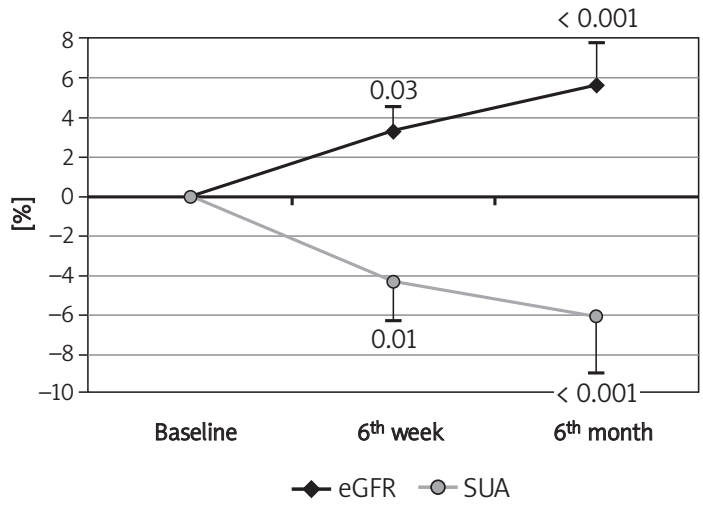

Figure 1. Time course of percent change $( \pm S D)$ in estimated glomerular filtration rate (eGFR) and serum uric acid (SUA) levels during the study 
several factors (e.g. DM, dyslipidaemia, hypertension, MetS and obesity) [26, 27]. Although CKD can progress to end-stage renal disease (ESRD), patients with stage 3 CKD are more likely to die of CVD before they reach ESRD, since CKD is per se a potent risk factor for CVD [28].

Meta-analyses have shown that statins slow the rate of eGFR decline in patients with $\operatorname{CKD}[28,29]$. The Heart Protection Study [30] and a pooled analysis of several pravastatin trials [31] showed that simvastatin and pravastatin reduce the rate of kidney function decline in patients with or at risk for CVD. In the Greek Atorvastatin and Coronary-heartdisease Evaluation (GREACE) study, we showed for the first time that atorvastatin treatment significantly increases eGFR whereas renal function deteriorated in untreated patients with coronary heart disease (CHD) with or without MetS and with or without DM $[12,14,15]$. This improvement in renal function was independently associated with a reduction in CVD events [12]. This benefit of atorvastatin treatment was confirmed in the Treating to New Targets (TNT) trial in 10,001 patients with stable CHD [32, 33]. In stage 3 CKD patients in TNT, the increase in eGFR was significantly greater with atorvastatin $80 \mathrm{mg} / \mathrm{d}$ than with $10 \mathrm{mg} /$ day (9.9 vs. $6.6 \%$, respectively; $p<0.005$ ), suggesting that this benefit is dose-related [32]. Moreover, the 3,107 patients who had CKD at baseline demonstrated greater CVD comorbidity than those with normal eGFR $(n=6,549)$ [33]. Compared with atorvastatin $10 \mathrm{mg} /$ day, atorvastatin $80 \mathrm{mg} /$ day reduced the relative risk of major CVD events significantly more in those with CKD (by $32 \%$ vs. $15 \%$ in those with normal renal function) [33]. The Collaborative Atorvastatin Diabetes Study (CARDS) [34] was a randomized placebo-controlled trial that included 2,838 patients with type $2 \mathrm{DM}$ and no prior CVD. At baseline, $34 \%$ of patients had an eGFR of 30-59 $\mathrm{ml} / \mathrm{min} / 1.73 \mathrm{~m}^{2}$, and in those patients atorvastatin $10 \mathrm{mg} / \mathrm{d}$ was associated with a modest improvement in the annual change in eGFR ( $p=0.01)$, and with substantial (42\%) reduction in major CVD events [34].

Studies with other hypolipidaemic drugs did not show any improvement in renal function. The SHARP trial included mostly patients with pre-dialysis renal function (only $36 \%$ of patients had stage 3 CKD, while the rest had stage 4 or 5 (mean eGFR $26.6 \mathrm{ml} / \mathrm{min} / 1.73 \mathrm{~m}^{2}$ ) [19]). These patients seem to have crossed the point of no return $[8,10,16]$ in terms of kidney function, while LDL-C reduction was modest $(33 \mathrm{mg} / \mathrm{dl})$. Nevertheless, in SHARP there was a significant reduction in clinical events [19]. In the Cholesterol and Recurrent Events (CARE) Trial [35], among all CHD dyslipidaemic individuals with an eGFR $<60 \mathrm{ml} / \mathrm{min} / 1.73 \mathrm{~m}^{2}$ ), the eGFR decline in the pravastatin group was not significantly differ- ent from that in the placebo group. Moreover, in the Antihypertensive and Lipid-Lowering Treatment to Prevent Heart Attack Trial (ALLHAT) [36] in hypertensive patients with moderate dyslipidaemia and decreased eGFR, pravastatin was not superior to usual care in preventing renal outcomes. This was consistent across the strata of baseline eGFR. However, benefit from statin therapy may depend on the degree of the cholesterol level decrease achieved [36], and pravastatin (40 mg/day over 4.8 years) only produced a $<10 \%$ fall in total cholesterol. The Veterans' Affairs High-Density Lipoprotein Intervention Trial (VA-HIT) study [37] was a randomized trial of gemfibrozil vs. placebo in 2531 men with established CAD; 1046 men had CKD (most had stage 2 and a few stage 3 CKD). The risk of sustained increases in serum creatinine was increased in gemfibrozil recipients compared with placebo (5.9\% vs. $2.8 \%, p=0.02$ ) [37]. Fenofibrate caused an acute, sustained plasma creatinine increase in the Fenofibrate Intervention and Event Lowering in Diabetes (FIELD) and Action to Control Cardiovascular Risk in Diabetes (ACCORD) studies [38]. However, fenofibrate reduced albuminuria and slowed estimated eGFR loss over 5 years, despite initially and reversibly increasing plasma creatinine [38]. It should be kept in mind that fibrates are metabolised in the kidney and stage 3 CKD or greater might cause toxic accumulation of fibrates or their metabolites in the blood [38]. The Assessment of Lescol in Renal Transplantation (ALERT) trial investigated the effect of fluvastatin treatment on renal function in renal transplant recipients [39]. Fluvastatin had no detrimental effect on renal function, or the risk of renal AEs, in renal transplant recipients with or without diabetes enrolled in ALERT. However, these findings could not be generalized because they were found in a special population. Based on all the above, it seems that the effect of a hypolipidaemic drug on renal function depends on baseline renal function, $L D L-C$ reduction, the drug category (statin or fibrate), the specific drug, and the dose used [16].

In the present study we recorded an increase in eGFR and a reduction in SUA levels by the $6^{\text {th }}$ treatment week (titration visit; Figure 1). This early benefit, which may be attributed to the pleiotropic effects of statins, was also apparent in the GREACE study $[12,14,15]$. Our findings in the present analysis confirm this benefit in a variety of high-risk patients.

A meta-analysis showed that intentional modest weight loss may reduce proteinuria and blood pressure but does not affect the eGFR [40]. However, this could be viewed as a beneficial effect because a decline in eGFR occurred in the control groups of the included studies, while the eGFR did not change during a mean follow-up of 7.4 months 
in patients who lost weight. Thus, weight loss might reduce the risk for both CVD and CKD [41]. In addition, in patients with CKD, weight loss reduced proteinuria and blood pressure and appeared to prevent further decline in renal function $[40,41]$. Therefore, the $6 \%$ weight loss that we observed in the present analysis because of lifestyle advice and the use of orlistat in some patients $(n=512)$ might have contributed to renoprotection.

There is accumulating evidence that dysglycaemia without DM is also associated with renal injury [42-44]. Furthermore, the prevalence of CKD rises gradually as fasting glucose levels increase, even well below the currently accepted threshold of $126 \mathrm{mg} / \mathrm{dl}$ for diagnosing DM [44]. This correlation remained significant after adjustment for age, gender, ethnic group and the presence of hypertension [44]. Thus, the reduction in fasting glucose levels in our patients because of lifestyle advice and treatment with metformin in some patients $(n=452)$ might have played a role in the improvement in renal function.

The effective management of hypertension might also have contributed to renoprotection in our analysis [45]. The increased activity of the reninangiotensin-aldosterone system (RAAS) is a key factor in the progression of CKD [46]. Angiotensin II mediates systemic haemodynamic changes [47] and plays an important role in promoting proteinuria and progressive eGFR decline [47]. Therefore, lowering blood pressure with drugs that block the RAAS is useful in the management of patients with CKD [47]. Thus, the use of RAAS blocking agents in $78 \%$ of our patients might have contributed to the increase in eGFR.

Elevated SUA levels were related to increased CVD risk in patients with MetS [48], non-alcoholic fatty liver disease [49], CKD [50], CVD [51] and in the general population [52]. A study with 14,262 person-years in patients with or without CVD (43\% and $57 \%$, respectively) showed that for each $1 \mathrm{mg} / \mathrm{dl}$ increase in SUA levels there was a $26 \%$ increase (adjusted for multiple CVD risk factors) in the risk of death [53]. Atorvastatin lowers SUA levels and we have reported a $29 \%$ increase in CVD events for every $1 \mathrm{mg} / \mathrm{dl}$ increase in SUA levels and a $24 \%$ reduction in CVD events for every $1 \mathrm{mg} / \mathrm{dl}$ atorvastatin-induced decrease in SUA levels [13]. In the Losartan Intervention for Endpoint reduction in hypertension (LIFE) study that compared losartan with atenolol [54, 55], a 29\% reduction in CVD events was attributed to losartan-induced reduction in SUA levels $[53,54]$. In the present analysis, $13 \%$ of patients were on losartan.

The present analysis has limitations. One is that this is a post hoc analysis of the effects of multifactorial treatment on renal function and SUA levels. Moreover, proteinuria and albuminuria, 2 param- eters that may significantly influence CVD as well as CKD risk, were not quantitatively assessed. The short duration of the study is not a limitation because we aimed to assess how soon these effects become apparent. Changes in eGFR may be due to functional or structural changes. In the long term, the structural changes are the important ones. We have shown in the past that this multifactorial therapeutic approach, including a statin, results in an increase of eGFR and in a reduction in SUA levels $[12,17]$. What was not known was the short-term (6 month) effect, which might mainly derive from functional changes. There was no control group because all patients were at high CVD risk and we considered that it was unethical to deprive them of appropriate treatment. Data at the $6^{\text {th }}$ month were compared with those of baseline. Another option was to use a control group on "usual care" and compare the $6^{\text {th }}$ month analysis results with the "structured care" group. In this context, it is relevant that all patients were on "usual care" prior to recruitment to the 5 studies. Besides, the last trials for multiple risk factor intervention using "usual care" were performed during the 1970s [Multiple risk factor intervention trial (MRFIT) [56] and the Hypertension Detection and Follow-up Program (HDFP) [57]], when both the exact impact of each CVD risk factor and the benefit from reversing it were not entirely clear. Data from the post hoc analysis of the data from the Justification for the Use of Statins in Prevention (JUPITER) trial (it included 17,802 healthy men and women) were used to predict statin treatment effect for individual patients based on existing risk level [58]. The accuracy of the prediction suggests that our conclusions on "best practice" benefit may be generalised.

In conclusion, this post hoc joint analysis of 5 prospective "best practice studies" showed that multifactorial intervention in patients with multiple CVD risk factors and stage 3 CKD improves renal function and lowers SUA levels early after treatment initiation (within 6 months), thus offsetting 2 potential CVD risk factors. According to the National Kidney Foundation, individuals with MetS, DM, hypertension, dyslipidaemia and the elderly are at high risk for CKD [1, 4]. Therefore, these patients should be managed aggressively and the present findings suggest that multifactorial intervention is beneficial in this regard.

\section{Acknowledgments}

We thank the following employees of the Regional (Bureau) Authority of the Ministry of Health for Northern Greece-Central Macedonia for their contribution to the 4 studies: A. Trichopoulou, Department Head and D. Florinis, K. Kakafika.

The ATTEMPT study was conducted under the auspices of the Hellenic Atherosclerosis Society and 
was sponsored by Pfizer Hellas through an independent research grant. We thank Dr Papageorgiou A. for carrying out the statistical analysis.

DPM has received research grants, from Genzyme, AstraZeneca, and MSD, he is an Advisor of MSD, and he is in the Speakers Bureau of MSD and Genzyme; VGA has received research grants from Pfizer, and he is an Advisor of MSD and AstraZeneca. The rest of the authors have no disclosures to report.

We thank the following physicians for providing patient data. Alihanidou O, Anagnostis P, Anthimidis G, Baharoudis G, Balaouri A, Baltatzi M, Bitli A, Charalambous C, Chatzikaloudi V, Chimonas T, Didangelos TP, Dimitroulia C, Dimopoulou S, Dolgyras S, Drakidis T, Economou K, Eythimiadou E, Florentin M, Foundakis G, Gaitanaki K, Giannakopoulou V, Gianoglou G, Giovas P, Giouleme O, Gossios T, Griva T, Hartaba E, Hastas D, Hatimi E, Iliadis F, loannou D, Kalafati A, Kakagias N, Kamilali C, Kapnia E, Koumaras C, Kotzamani A, Liberopoulos EN, Liopirakis A, Limenopoulos V, Malias I, Mandikou E, Makridis A, Matsiras S, Matziris A, Michailidou K, Mitsiou E, Paletas K, Pankourelias E, Papadopoulos G, Papageorgiou A, Papalexiou H, Papastefanou E, Papathanakis C, Pehlivanidis A, Pipertzis G, Psaris P, Rudolf J, Samouilidou M, Stefanidou K, Sterioula E, Theodosiou G, Thoma E, Tsitsiou E, Taplidis A, Tsakoudakis N, Vasiliadis P, Volonakis P, Vosnakidis T, Zantidis A

ClinicalTrials.gov ID of original studies: NCT00416611, NCT00416741.

\section{References}

1. Chronic Kidney Disease (CKD). National Kidney Foundation. Available at: http://www.kidney.org/kidneyDisease/ ckd/index.cfm. Accessed August 6, 2011.

2. National Kidney Foundation. K/DOQI clinical practice guidelines for chronic kidney disease: evaluation, classification, and stratification. Am J Kidney Dis 2002; 39 (suppl 1): S1-266.

3. Coresh J, Selvin E, Stevens LA, et al. Prevalence of chronic kidney disease in the United States. JAMA 2007; 298: 2038-47.

4. Levey AS, Coresh J, Balk E, et al.; National Kidney Foundation. National Kidney Foundation practice guidelines for chronic kidney disease: evaluation, classification, and stratification. Ann Intern Med 2003; 139: 137-47.

5. Coresh J, Astor BC, Greene T, Eknoyan G, Levey AS. Prevalence of chronic kidney disease and decreased kidney function in the adult US population: Third National Health and Nutrition Examination Survey. Am J Kidney Dis 2003; 41: 1-12.

6. Go AS, Chertow GM, Fan D, McCulloch CE, Hsu CY. Chronic kidney disease and the risks of death, cardiovascular events, and hospitalization. N Engl J Med 2004; 351: 1296-305.

7. Chronic Kidney Disease Prognosis Consortium, Matsushita K, van der Velde M, Astor BC, et al. Association of estimated glomerular filtration rate and albuminuria with all-cause and cardiovascular mortality in general population cohorts: a collaborative meta-analysis. Lancet 2010; 375: 2073-81.
8. Efstratiadis G, Tziomalos K, Mikhailidis DP, Athyros VG, Hatzitolios A. Atherogenesis in renal patients: a model of vascular disease? Curr Vasc Pharmacol 2008; 6: 93-107.

9. Astor BC, Hallan SI, Miller ER 3rd, Yeung E, Coresh J. Glomerular filtration rate, albuminuria, and risk of cardiovascular and all-cause mortality in the US population. Am J Epidemiol 2008; 167: 1226-34.

10. Tziomalos K, Ganotakis ES, Gazi IF, Nair DR, Mikhailidis DP. Kidney function and estimated vascular risk in patients with primary dyslipidemia. Open Cardiovasc Med J 2009 16; 3: 57-68.

11. Black C, Sharma P, Scotland G, et al. Early referral strategies for management of people with markers of renal disease: a systematic review of the evidence of clinical effectiveness, cost-effectiveness and economic analysis. Health Technol Assess 2010; 14: 1-184.

12. Athyros VG, Mikhailidis DP, Papageorgiou AA, et al. The effect of statins versus untreated dyslipidaemia on renal function in patients with coronary heart disease. A subgroup analysis of the Greek atorvastatin and coronary heart disease evaluation (GREACE) study. J Clin Pathol 2004; 57: 728-34.

13. Athyros VG, Elisaf M, Papageorgiou AA, et al.; GREACE Study Collaborative Group. Effect of statins versus untreated dyslipidemia on serum uric acid levels in patients with coronary heart disease: a subgroup analysis of the GREek Atorvastatin and Coronary-heart-disease Evaluation (GREACE) study. Am J Kidney Dis 2004; 43: 589-99.

14. Athyros VG, Mikhailidis DP, Liberopoulos EN, et al. Effect of statin treatment on renal function and serum uric acid levels and their relation to vascular events in patients with coronary heart disease and metabolic syndrome: a subgroup analysis of the GREek Atorvastatin and Coronary heart disease Evaluation (GREACE) Study. Nephrol Dial Transplant 2007; 22: 118-27.

15. Athyros VG, Papageorgiou AA, Elisaf M, Mikhailidis DP; GREACE Study Collaborative Group. Statins and renal function in patients with diabetes mellitus. Curr Med Res Opin 2003; 19: 615-7.

16. Athyros VG, Karagiannis A, Kakafika A, Elisaf M, Mikhailidis DP. Statins and renal function. Is the compound and dose making a difference? Nephrol Dial Transplant 2007; 22: 963-4.

17. Athyros VG, Karagiannis A, Ganotakis ES, et al.; for the Assessing The Treatment Effect in Metabolic syndrome without Perceptible diabeTes (ATTEMPT) Collaborative Group. Association between the changes in renal function and serum uric acid levels during multifactorial intervention and clinical outcome in patients with metabolic syndrome. A post hoc analysis of the ATTEMPT study. Curr Med Res Opin doi:10.1185/03007995.2011.595782.

18. Samuelsson O, Mulec H, Knight-Gibson C, et al. Lipoprotein abnormalities are associated with increased rate of progression of human chronic renal insufficiency. Nephrol Dial Transplant 1997; 12: 1908-15.

19. Baigent C, Landray MJ, Reith C, et al.; the SHARP Investigators. The effects of lowering LDL cholesterol with simvastatin plus ezetimibe in patients with chronic kidney disease (Study of Heart and Renal Protection): a randomised placebo-controlled trial. Lancet 2011; 377: 2181-92.

20. Hatzitolios Al, Athyros VG, Karagiannis A, et al.; IMPROVE Collaborative Group. Implementation of strategy for the management of overt dyslipidemia: the IMPROVE-dyslipidemia study. Int J Cardiol 2009; 134: 322-9.

21. Athyros VG, Karagiannis A, Hatzitolios Al, et al.; SAGEMETS collaborative group. Standardized arrangement for 
a guideline-driven treatment of the metabolic syndrome: the SAGE-METS study. Curr Med Res Opin 2009; 25: 971-80.

22. Karagiannis A, Hatzitolios Al, Athyros VG, et al. Implementation of guidelines for the management of arterial hypertension. The IMPULSION study. Open Cardiovasc Med J 2009; 3: 26-34

23. Athyros VG, Hatzitolios A, Karagiannis A, et al.; INDEED Collaborative Group. Initiative for a new diabetes therapeutic approach in a Mediterranean country: the INDEED study. Curr Med Res Opin 2009; 25: 1931-40.

24. Grundy SM, Cleeman JI, Daniels SR, et al.; American Heart Association; National Heart, Lung, and Blood Institute. Diagnosis and management of the metabolic syndrome: an American Heart Association/National Heart, Lung, and Blood Institute Scientific Statement. Circulation 2005; 112: 2735-52.

25. Levey AS, Bosch JP, Lewis JB, Greene T, Rogers N, Roth D. A more accurate method to estimate glomerular filtration rate from serum creatinine: a new prediction equation. Modification of Diet in Renal Disease Study Group. Ann Intern Med 1999; 130: 461-70.

26. Navaneethan SD, Pansini F, Perkovic V, et al. HMGCoA reductase inhibitors (statins) for people with chronic kidney disease not requiring dialysis. Cochrane Database Syst Rev 2009; 2: CD007784.

27. Agarwal R. Effects of statins and renal function. Mayo Clin Proc 2007; 82: 1381-90.

28. Sarnak MJ, Levey AS, Schoolwerth AC, et al. Kidney disease as a risk factor for development of cardiovascular disease: a statement from the American Heart Association Councils on Kidney in Cardiovascular Disease, High Blood Pressure Research, Clinical Cardiology, and Epidemiology and Prevention. Circulation 2003; 108: 2154-69.

29. Sandhu S, Wiebe N, Fried LF, Tonelli M. Statins for improving renal outcomes: a meta-analysis. J Am Soc Nephrol 2006; 17: 2006-16

30. Collins R, Armitage J, Parish S, et al. MRC/BHF Heart Protection Study of cholesterol-lowering with simvastatin in 5963 people with diabetes: a randomised placebo-controlled trial. Lancet 2003; 361: 2005-16.

31. Tonelli M, Isles C, Craven T, et al. Effect of pravastatin on rate of kidney function loss in people with or at risk for coronary disease. Circulation 2005; 112: 171-8.

32. Shepherd J, Kastelein JJ, Bittner V, et al.; Treating to New Targets Investigators. Effect of intensive lipid lowering with atorvastatin on renal function in patients with coronary heart disease: the Treating to New Targets (TNT) study. Clin J Am Soc Nephrol 2007; 2: 1131-9.

33. Shepherd J, Kastelein JJ, Bittner V, et al.; TNT (Treating to New Targets) Investigators. Intensive lipid lowering with atorvastatin in patients with coronary heart disease and chronic kidney disease: the TNT (Treating to New Targets) study. J Am Coll Cardiol 2008; 51: 1448-54.

34. Colhoun HM Betteridge DJ, Durrington PN, et al., CARDS Investigators. Effects of atorvastatin on kidney outcomes and cardiovascular disease in patients with diabetes: an analysis from the Collaborative Atorvastatin Diabetes Study (CARDS). Am J Kidney Dis 2009; 54: 810-9.

35. Tonelli M, Moyé L, Sacks FM, Cole T, Curhan GC; Cholesterol and Recurrent Events Trial Investigators. Effect of pravastatin on loss of renal function in people with moderate chronic renal insufficiency and cardiovascular disease. J Am Soc Nephrol 2003; 14: 1605-13.

36. Rahman M, Baimbridge C, Davis BR, et al.; ALLHAT Collaborative Research Group. Progression of kidney disease in moderately hypercholesterolemic, hypertensive patients randomized to pravastatin vs. usual care: report from the Antihypertensive and Lipid-Lowering Treatment to Prevent Heart Attack Trial (ALLHAT). Am J Kidney Dis 2008; 52: 412-24.

37. Tonelli M, Collins D, Robins S, Bloomfield H, Curhan GC; Veterans' Affairs High-Density Lipoprotein Intervention Trial (VA-HIT) Investigators. Gemfibrozil for secondary prevention of cardiovascular events in mild to moderate chronic renal insufficiency. Kidney Int 2004; 66: 1123-230.

38. Davis TM, Ting R, Best JD, et al.; Fenofibrate Intervention and Event Lowering in Diabetes Study investigators. Effects of fenofibrate on renal function in patients with type 2 diabetes mellitus: the Fenofibrate Intervention and Event Lowering in Diabetes (FIELD) Study. Diabetologia 2011; 54: 280-90.

39. Fellström B, Abedini S, Holdaas H, Jardine AG, Staffler B, Gimpelewicz C; Assessment of Lescol in Renal Transplantation (ALERT) study group. No detrimental effect on renal function during long-term use of fluvastatin in renal transplant recipients in the Assessment of Lescol in Renal Transplantation (ALERT) study. Clin Transplant 2006; 20: 732-9.

40. Navaneethan SD, Yehnert H, Moustarah F, Schreiber MJ, Schauer PR, Beddhu S. Weight loss interventions in chronic kidney disease: a systematic review and meta-analysis. Clin J Am Soc Nephrol 2009; 4: 1565-74.

41. Kramer H, Tuttle KR, Leehey D, et al. Obesity management in adults with CKD. Am J Kidney Dis 2009; 53: 151-65.

42. Singleton JR, Smith AG, Russell JW, Feldman EL. Microvascular complications of impaired glucose tolerance. Diabetes 2003; 52: 2867-73.

43. Gabir MM, Hanson RL, Dabelea D, et al. Plasma glucose and prediction of microvascular disease and mortality: evaluation of 1997 American Diabetes Association and 1999 World Health Organization criteria for diagnosis of diabetes. Diabetes Care 2000; 23: 1113-8.

44. Nang EE, Khoo CM, Tai ES, et al. Is there a clear threshold for fasting plasma glucose that differentiates between those with and without neuropathy and chronic kidney disease: the Singapore Prospective Study Program. Am J Epidemiol 2009; 169: 1454-62.

45. Palmer BF, Fenves AZ. Optimizing blood pressure control in patients with chronic kidney disease. Proc (Bayl Univ Med Cent) 2010; 23: 239-45.

46. Jafar TH, Stark PC, Schmid CH, et al.; the AIPRD Study Group. Progression of chronic kidney disease. The role of blood pressure control, proteinuria, and angiotensin-converting enzyme inhibition. A patient-level meta-analysis. Ann Intern Med 2003; 139: 244-52.

47. Griffin KA, Bidani AK. Progression of renal disease: renoprotective specificity of renin-angiotensin system blockade. Clin J Am Soc Nephrol 2006; 1: 1054-65.

48. Tsouli SG, Liberopoulos EN, Mikhailidis DP, Athyros VG, Elisaf MS. Elevated serum uric acid levels in metabolic syndrome: an active component or an innocent bystander? Metabolism 2006; 55: 1293-301.

49. Katsiki N, Athyros VG, Karagiannis A, Mikhailidis DP. Hyperuricaemia and non-alcoholic fatty liver disease (NAFLD): a relationship with implications for vascular risk? Curr Vasc Pharmacol 2011 Mar 10. [Epub ahead of print].

50. Kang DH, Nakagawa T, Feng $L$, et al. A role for uric acid in the progression of renal disease. J Am Soc Nephrol 2002; 13: 2888-97.

51. Bickel C, Rupprecht HJ, Blankenberg S, et al. Serum uric acid as an independent predictor of mortality in patients 
with angiographically proven coronary artery disease. Am J Cardiol 2002; 89: 12-7.

52. Fang J, Alderman MH. Serum uric acid and cardiovascular mortality the NHANES I epidemiologic follow-up study, 1971-1992. National Health and Nutrition Examination Survey. JAMA 2000; 283: 2404-10.

53. loachimescu AG, Brennan DM, Hoar BM, Hazen SL, Hoogwerf BJ. Serum uric acid is an independent predictor of all-cause mortality in patients at high risk of cardiovascular disease: a preventive cardiology information system (PreCIS) database cohort study. Arthritis Rheum 2008; 58: 623-30.

54. Hoieggen A, Alderman MH, Kjeldsen SE, et al.; LIFE Study Group. The impact of serum uric acid on cardiovascular outcomes in the LIFE study. Kidney Int 2004; 65: 1041-9.

55. Daskalopoulou SS, Athyros VG, Elisaf M, Mikhailidis D. The impact of serum uric acid on cardiovascular outcomes in the LIFE study. Kidney Int 2004; 66: 1714-5.

56. Multiple Risk Factor Intervention Trial Research Group. Multiple risk factor intervention trial. Risk factor changes and mortality results. JAMA 1982; 248: 1465-77.

57. Tyroler HA, Ford CE. Serum cholesterol and coronary heart disease risk in female and older hypertensives. The experience under usual community care in the Hypertension Detection and Follow-up Program. Ann Epidemiol 1992; 2: $155-60$.

58. Dorresteijn JA, Visseren FL, Ridker PM, et al. Estimating treatment effects for individual patients based on the results of randomised clinical trials. BMJ 2011 Oct 3; 343: d5888. doi: 10.1136/bmj.d5888. 